()

\title{
Focused versus screening CT scans for evaluation of nontraumatic abdominal pain in the emergency department
}

ORIGINAL RESEARCH

\author{
Kristy Thurston \\ Suma Magge \\ Robert Fuller \\ Anthony Voytovich \\ Jessica Lee \\ Robert Kozol \\ University of Connecticut School \\ of Medicine, Farmington, \\ CT, USA
}

\author{
This article was published in the following Dove Press journal: \\ Open Access Emergency Medicine \\ 31 March 2010 \\ Number of times this article has been viewed
}

Correspondence: Robert Kozol JFK Medical Center, 530I South Congress Ave, Atlantis, FL 33462, USA

Tel $+|56| 548 \mid 425$

Fax $+|56| 548 \mid 572$

Email rakozol@gmail.com
Objective: To evaluate the utility of computed tomography (CT) scans in patients with abdominal pain in the emergency department. We compared focused scans (having a single diagnosis in mind) and screening scans (having no diagnosis or more than one diagnosis in mind) with the hypothesis that focused scans will reveal pathology more often than screening scans. Treatment plans and patient outcomes were also compared between the two populations.

Methods: This is a prospective study in which 100 patients who presented to an academic medical center with abdominal pain and underwent an abdominal CT were enrolled in the study. A chart review was later completed to gather ultimate outcome data for each of the enrolled subjects.

Results: Of the 61 patients having a focused CT, pathology was identified on $63.9 \%$ of the scans, which did not differ significantly from the $65.4 \%$ of scans that revealed pathology in the screening group. In the focused group, anticipated admissions were reduced, but the reduction was not significant. The screening group did show a significant difference, with eight fewer patients being admitted than initially planned. The total number of patients deemed to require admission was significantly reduced by $15 \%$ following all CT scans.

Conclusion: While there was no difference between the focused and screening groups in the rate of identifying pathology, there was a significant decline in number of patients requiring admission to the hospital in the "screening" CT group (when comparing emergency physicians' pre- and post-CT treatment plans).

Keywords: acute abdominal pain, computed tomography, focused, screening, emergency department

\section{Introduction}

Abdominal pain unrelated to trauma is a common presentation in the emergency department. Proper management of patients with acute abdominal pain requires consideration of the patient's history and physical findings, laboratory data, and imaging studies. ${ }^{1}$ Clinical assessment remains the most important first step in evaluating patients with an acute abdomen; however, it has been found to yield an accurate diagnosis in only $47 \%-76 \%$ of patients. ${ }^{2,3}$ Even the most experienced surgeon will make the correct diagnosis in only four out of five cases. This figure falls to $50 \%$ among trainees and doctors working in the community. ${ }^{4}$ It has been shown that computed tomography (CT) scanning can expedite the diagnostic process. Indeed, many of the most common causes of acute abdomen are readily identified by CT scanning, as are their complications. ${ }^{5-7}$ While the accuracy of CT scans has been demonstrated in previous studies, ${ }^{8,9}$ best practices for use of CT scans in this setting are unclear. Thus there is a debate about when and how often to use CT scans to assist in making the diagnosis in patients with acute abdominal pain. 
Delays in diagnosis may affect morbidity and mortality, and may have a significant effect on resource utilization. The outcome of this study may help clinicians to decide on when to use CT scans in patients with acute abdominal pain. The primary goal of this study was to compare patient outcomes after focused scans (having one particular diagnosis in mind) versus screening scans (having no or more than one diagnosis in mind). Our hypothesis was that focused scans will reveal pathology more often than will screening scans.

\section{Methods}

Between June 2003 and July 2004, 100 patients who presented with nontraumatic acute abdominal pain to the emergency room at the University of Connecticut Health Center were prospectively enrolled in the study. All patients who had a complete abdominal CT scan were deemed eligible for the study. Emergency room physicians were asked to complete a four-item fact-finding questionnaire addressing the following: clinical signs and symptoms, presumptive diagnosis, and pre-/post-CT treatment plans. A focused CT request was defined as one where the ordering physician had one specific diagnosis in mind. A screening CT request was defined as one where there was no diagnosis or multiple diagnoses in mind.

In January of 2007, patient charts were reviewed to evaluate outcomes, specifically admission to the hospital versus discharge from the emergency department, length of stay, procedures, and mortality.

Ultimately, six of the 100 patients were excluded from the study because of incomplete questionnaires. Seven of the 94 charts were either incomplete or unavailable and thus were not included in the final analysis. This left a total of 87 patients in the study. Characteristics of these subjects can be seen in Table 1.

Statistical analysis was carried out using the two-tailed $t$-test to compare group means and the $z$ test to compare proportions. This study was approved by the Institutional Review Board of the University of Connecticut.

\section{Results}

Of the 87 patients presenting with abdominal pain, 61 (70.1\%) of them had a focused abdominal CT, with the

Table I Patient characteristics

\begin{tabular}{llll}
\hline Characteristic & $\begin{array}{l}\text { Focused } \\
(\mathbf{n}=\mathbf{6 I})\end{array}$ & $\begin{array}{l}\text { Screening } \\
(\mathbf{n}=\mathbf{2 6})\end{array}$ & P value \\
\hline Age (years) & 52.5 & 52.7 & 0.97 \\
Gender & & & 0.32 \\
Male $(\mathrm{n}, \%)$ & $19(3 \mathrm{I})$ & $1 \mathrm{I}(42)$ & \\
Female $(\mathrm{n}, \%)$ & $42(69)$ & $15(58)$ & \\
\hline
\end{tabular}

remaining 26 having a screening abdominal CT. Of the 61 patients having a focused CT, pathology was identified on 39 of the scans $(63.9 \%)$ with the remaining scans being read as "no pathology present". This is not significantly different from the $65.4 \%$ of scans that revealed pathology in the screening group $(P=0.9)$. Of the 39 scans that showed pathology, 23 (59\%) confirmed the emergency department physician's primary diagnosis.

There were no significant differences in outcomes between the focused and screening groups. The percentage of patients admitted, percentage of patients undergoing procedures, length of stay, and mortality were similar between the cohorts (see Table 2).

Issues of patient management were also evaluated, with the questionnaire including pre- and post-CT treatment plans (admission versus nonadmission). The total number of patients admitted was significantly reduced following all CT scans $(P=0.049)$. In the focused group, admissions were reduced, however, this did not show a significant difference compared with pre-CT planning $(P=0.36)$. The screening group did show a significant difference, with eight fewer patients being admitted than initially planned $(P=0.03$, see Table 3$)$.

\section{Discussion}

There has been much debate over how and when to use CT scans to augment diagnosis and care in the emergency department. A retrospective study done in 2002 looked at adult emergency patients who underwent abdominal CT for a variety of nontraumatic indications. Findings in less than half of the patients supported the pretest clinical suspicion, and an alternative previously unsuspected diagnosis was suggested in $13 \% .{ }^{10}$ A prospective study done in 2003 evaluating the value of CT scans in the emergency department showed that prior to $\mathrm{CT}$, the management plan included hospital admission for 402 patients. Following CT, only 312 patients were actually admitted. Thus, the net impact of performing $\mathrm{CT}$ was to obviate the need for hospital admission in 90 of $536(17 \%)$ of patients with abdominal pain. Prior to CT, 67 of 536 (13\%) of all patients would have undergone

Table 2 Outcomes between the focused and screening groups

\begin{tabular}{llll}
\hline & $\begin{array}{l}\text { Focused } \\
(\mathbf{n}=\mathbf{6 1})\end{array}$ & $\begin{array}{l}\text { Screening } \\
(\mathbf{n}=\mathbf{2 6})\end{array}$ & $\mathbf{P}$ value \\
\hline $\begin{array}{l}\text { Pathology on computed } \\
\text { tomography (n, \%) }\end{array}$ & $39(63.9)$ & $17(65.4)$ & 0.90 \\
Patients admitted (n, \%) & $25(41.0)$ & $10(38.5)$ & 0.83 \\
Procedure (n, \%) & $17(27.9)$ & $7(26.9)$ & 0.93 \\
Length of stay (days) & 5.8 & 8.7 & 0.21 \\
Mortality (n) & $\mathrm{I}$ & 0 & \\
\hline
\end{tabular}


Table 3 Patient admission data pre- and post- computed tomography (CT)

\begin{tabular}{llll}
\hline & Pre-CT & Post-CT & P value \\
\hline $\begin{array}{l}\text { Total patients planned for } \\
\text { admission (n, \%) }\end{array}$ & $48 / 87(55.2)$ & $35 / 87(40.2)$ & 0.049 \\
Focused group (n, \%) & $30 / 6 \mid(49.2)$ & $25 / 6 \mid(4 I .0)$ & 0.36 \\
Screening group (n, \%) & $18 / 26(69.2)$ & $10 / 26(38.5)$ & 0.03 \\
\hline
\end{tabular}

immediate surgery; however, following CT only 25 (5\%) actually required immediate surgery. ${ }^{11}$

The goal of this study was to compare outcomes in patients with abdominal pain based on whether they had a "focused" versus "screening" CT scan. Fifty-nine percent of the time, the focused CT confirmed the physician's primary diagnosis - a higher percentage than has been seen in a number of previous studies. While there was no difference between the focused and screening groups in detection of pathology, procedures, admission, length of stay, and mortality, there was a significant difference in patient management. CT scans eliminated pre-CT admission plans in both arms of the study (even more so in the screening CT group). This correlates with previous findings, ${ }^{12,13}$ including a prospective study performed in 2004 which showed that early CT scan altered patient management in $58 \%$ of their cohort and prevented emergent laparotomy in $28 \% .{ }^{12}$ There was a significant decline in number of patients requiring admission to the hospital when comparing pre-CT with post-CT treatment plan in the total cohort and the screening group. This finding confirms a previous study. ${ }^{11}$ Such a decline in admissions is clearly of value in a time and place where both financial resources and number of beds are stretched very thin. Thus with the screening, or shotgun approach, CT scans may prove to be efficient given that they detect pathology at the same rate as the focused scans and serve to significantly limit the number of admissions. In fact, a retrospective study of over 2000 patients supported the use of routine early CT scanning in patients with abdominal pain. ${ }^{14}$

It is acknowledged that this study was not blinded, and hence there may have been implied pressure to be thinking of a precise diagnosis, thus placing more patients in the "focused" CT scan group. In addition, the study was not designed for cost analysis, which would have been of great interest to the journal audience.

The use of routine (or "screening") CT scans is frequently frowned upon from both an intellectual as well as a cost perspective. While cost analysis was not an aim of this study, one could anticipate cost savings in light of admissions avoided and this is certainly worthy of future investigation.

\section{Disclosures}

The authors report no conflicts of interest in this work.

\section{References}

1. Carter P. The acute abdomen and its management. Hosp Med. 2000;61:688-689.

2. Ng CS, Watson CJ, Palmer CR, et al. Evaluation of early abdominopelvic computed tomography in patients with acute abdominal pain of unknown cause: Prospective randomized study. BMJ. 2002;325:1387.

3. Rosen MP, Sands DZ, Longmaid HE 3rd, et al. Impact of abdominal CT on the management of patients presenting to the emergency department with acute abdominal pain. Am J Roentgenol. 2000;174: 1391-1396.

4. Briton J. Acute abdomen. In: Morris PJ, Wood WC, editors. Oxford Textbook of Surgery. Oxford: Oxford University Press; 2000.

5. Michel H, Taourel P, Larrey D, Bruel JM. Acute abdomen of unknown origin: Impact of CT on diagnosis and management. Gastrointest Radiol. 1992;17:287-291.

6. Jones RS. Acute abdomen. In: Townsend CM, editor. Sabiston Textbook of Surgery. Eastbourne: WB Saunders Company; 2001:802.

7. Malone AJ. Unenhanced CT in the evaluation of the acute abdomen: The community hospital experience. Semin Ultrasound CT MR. 1999;20:68-76.

8. Siewert B, Raptopoulos V, Mueller MF, Rosen MP, Steer M. Impact of $\mathrm{CT}$ on diagnosis and management of acute abdomen in patients initially treated without surgery. Am J Roentgenol. 1997;168:173-178.

9. MacKersie AB, Lane MJ, Gerhardt RT, et al. Nontraumatic acute abdominal pain: Unenhanced helical CT compared with three-view acute abdominal series. Radiology. 2005;237:114-122.

10. Brown DF, Fischer RH, Novelline RA, Kim J, Nagurney JT. The role of abdominal computed tomography scanning in patients with nontraumatic abdominal symptoms. Eur J Emerg Med. 2002;9:330-333.

11. Rosen MP, Siewert B, Sands DZ, et al. Value of abdominal CT in the emergency department for patients with abdominal pain. Eur Radiol. 2003;13:418-424.

12. Salem TA, Molloy RG, O’Dwyer PJ, et al. Prospective study on the role of the CT scan in patients with an acute abdomen. Colorectal Dis. 2005;7:460-466

13. Tsushima Y, Yamada S, Aoki J, Motojima T, Endo K. Effect of contrastenhanced computed tomography on diagnosis and management of acute abdomen in adults. Clin Radiol. 2002;57:507-513.

14. Strömberg C, Johansson G, Adolfsson A. Acute abdominal pain: Diagnostic impact of immediate CT scanning. World J Surgery 2007;31:2347-2354

Open Access Emergency Medicine

\section{Publish your work in this journal}

Open Access Emergency Medicine is an international, peer-reviewed, open access journal publishing original research, reports, editorials, reviews and commentaries on all aspects of emergency medicine. The manuscript management system is completely online and includes a very quick and fair peer-review system, which is all easy to use.

\section{Dovepress}

Visit http://www.dovepress.com/testimonials.php to read real quotes from published authors. 